\title{
DIE VERHOUDING LIGGAAM EN HOOF
}

\section{BY PAULUS}

\author{
G. M. M. PELSER
}

\section{INLEIDEND}

Die aanduiding van die kerk as die liggaam van Christus is die mees tiperenae by Paulus') en die prominentste van al die N.T. beelde vir die kerk. Dit gee meer as ander N.T. beelde ' $n$ voller en ryker beskrywing van die wese, aard, funksie en bestemming van die kerk. Hierdie beeld vertoon verskillende fasette wat elkeen vanuit ' $n$ ander hoek lig werp op die realiteit wat dit aandui. Juis om hierdie rede is dit moeilik defineerbaar, indien moontlik, en het dit aanleiding gegee tot verskillende, dikwels grondig uiteenlopende interpretasies. ${ }^{2}$ ) Die doel van hierdie ondersoek is nie om die moontlike agtergronde van hierdie beeld te probeer aantoon ${ }^{3}$ ) of al die fasette daarvan te belig nie, maar om soos die titel hiervan aandui, slegs te vra na die verhouding of aard van die verhouding tussen die kerk as liggaam van Christus en Christus as die Hoof van hierdie liggaam. Dit beteken vanselfsprekend dat ons ondersoek beperk sal word tot die terrein van die Pauliniese literatuur, en meer bepaald nog sover dit die verhouding liggaam - Hoof raak tot die Efese - en Kolossensebrief. Hiermee word nie ontken dat daar in die res van die N.T. ook ander beelde of terme gebruik word wat dieselfde gedagte na vore bring nie, ${ }^{1}$ ) maar ons moet ons noodgedwonge beperk by die beeldgroep wat direkte relevansie het.

In die titel van hierdie ondersoek is verder aangekondig dat ons die betrokke verhouding wil nagaan soos Paulus dit sien. Dit hou in dat ons, minstens vir die doel van hierdie ondersoek, nie die Pauliniese outerskap van Efesiërs-Kolossense wil bevraagteken nie, al sou daar ook 'n opmerklike uitbreiding van die onderhawige saak by hierdie briewe voorkom in vergelyking met die gedagtekomplekse by Romeine en I Korinthiërs.

1) H. N. Ridderbos, Paulus. Ontwerp van zjin Theologie, Kampen 1971, p. 404.

2) Kyk P. S. Minear, Images of the Church in the New Testament, Philadelphia s.j. (1960), p. 173 v.; asook H. N. Ridderbos, a.w., p. 404; Kyk ook by J. J. Meuzelaar, Der Leib des Messias. Eine exeqetische Studie über den Gedanken vom Leib Christi in den Paulusbriefen, Assen 1961, p. 1 voetnoot 1 , vir die stroom van publikasies wat sedert die begin van hierdie eeu die lig oor hierdie onderwerp gesien het.

3) Kyk hiervoor bv. E. Schweizer, Die Kirche als Leib Christi in den Paulinischen Homologumena, Theologische Literaturzeitung, 86 jg. 1961, p. 162 vv.

1) Ons dink byvoorbeeld hier aan die wynstok-en-lote-beeld waarin daar miskien wel elemente opgesluit lê wat ook deur die liggaam-beeld na vore gebring word. 
Al sou Efesiërs-Kolossense ook as Deutero-Paulinies beskou word beteken dit nog dat hulle in die Pauliniese tradisie staan en daarom nie vreemd teenoor die Pauliniese teologie nie.

\section{BEELD OF WERKLIKHEID?}

'n Vraag wat eerste na vore kom met betrekking tot die sôma Christou beeld is: het ons hier te make bloot met 'n beeld of met die werklikheid self? Wil hierdie term dus slegs metafories die kerk met die menslike liggaam vergelyk of is dit 'n ontologiese uitspraak wat aandui wat die kerk in wese is naamlik die liggaam van Christus? Hierdie probleem geld nie slegs die liggaam-beeld nie maar ook talle ander beelde in die N.T.5) Indien dit slegs om metaforiese vergelyking gaan, is die vraag van verhouding of verbintenis tussen Hoof en liggaam nie ter sake nie behalwe in afgeleide sin. Hoewel sommige navorsers in die beeld niks meer as ' $n$ gelykenis of metafoor sien nie, word hedendaags deur die oorgrote meerderheid aanvaar dat dit hierin gaan om 'n reële werklikheid. Anders gestel, die gedagte is dat hier 'n realiteit ter sprake is, wat metafories uitgedruk word en wat reeds in Rom. 12 en I Kor. 12 'n dubbele betekenis het. Die gelowiges is dan die liggaam van Christus omdat hulle „in Christus" is, dit is die reële karakter van die term; maar soos die liggaam uit verskeie lede bestaan en tog een is, so ook die gemeente, dit is die metaforiese betekenis van die beeld. ${ }^{\circ}$ ) Die vraag mag ook gevra word of dit toelaatbaar en noodsaaklik is om beslissend vir die een of die ander te kies aangesien die N.T. dit self nie doen nie. Die bedoeling is t.o.v. verskeie beelde waarskynlik juis dat die metaforiese sowel as ontologiese karakter van 'n beeld raakgesien en gehonoreer moet word, anders gaan iets van die betekenis en verkondiging daarvan verlore..$^{i}$ )

\section{VERSKILLENDE INTERPRETASIES}

Om iets meer te begryp van die aard en omvang van ons probleem is dit nodig om kortliks kennis te neem van die verskillende interpretasies wat al geheg is aan die liggaam-beeld.

Dit beteken weer nie dat ons op die liggaam-beeld as sodanig wil toespits nie, maar daarna wil kyk met die oog op die implikasies wat ons verstaan daarvan vir die verstaan van die verhouding lig-

5) Vgl. bv. hieroor P. S. Minear se bespreking van die probleem in sy a.w., p. 18 vv.

6) Kyk J. J. Meuzelaar, a.w., p. 5 v. asook Q. Cullmann, Königsherrschaft Christi und Kirche im Neuen Testament (Theologische Studien. Heft. 10.). Zürich 1950, p. 29. "Die Bezeichnung "Leib' ist im Neuen Testament mehr als Bild, und das Leibsein der Kirche ist real gedacht ..."; A. Nygren, Der Römerbrief, "Göttingen 1965, p. 300 . ..Für Paulus ist sôma Christou, der Leib Christi', nicht ein Bild oder Gleichnis, sondern ein Bild oder Gleichnis, sondern eine unumstrittene Wirklichkeit..."

r) Vgl. P. S. Minear se m.i. korrekte siening van die saak in sy a.w., p. 20 v. 
gaam-Hoof sal hê. Ons kan nie, soos sommige graag wil doen, aanvaar dat hierdie beeld slegs die onderlinge verhoudinge tussen lede van die gemeente tot uitdrukking wil bring nie. Al is hierdie faset gewis in die beeld aanwesig, is die betekenis van die beeld daarmee nog nie uitgeput nie. Dit gaan veel verder en wil sonder twyfel 'n beskrywing gee van 'n besondere en noue relasie tussen Christus en sy kerk.

Dit is onmoontlik om, veral ook binne hierdie bestek, in te gaan op al die variasies van verklarings wat tot dusver aangebied is. ${ }^{\text {a }}$ ) Ons wil slegs aandag gee aan die meer algemeen voorkomende beskouinge. In hierdie opsig het $H$. N. Ridderbos ${ }^{8}$ ) 'n bruikbare samevatting gegee wat ons in hooftrekke hier wil aanstip.

In hoofsaak kan daar twee interpretasie-lyne onderskei word naamlik die verstaan van die beeld in oneintlike, kollektiewe sin en die verstaan daarvan in eintlike, persoonlike sin, terwyl elkeen ook nog sy eie variasies het.

(i) Die opvatting wat die uitdrukking ,liggaam van Christus" in oordragtelike sin verstaan is die mees tradisionele in sowel Rooms Katolieke Protestantse kring. Die gedagte is hier dat die term 'n figuurlike voorstelling is van die lewensgemeenskap van die gemeente met Christus. Liggaam is hier dus nie die persoonlike, historiese liggaam van Christus nie maar die gemeente as gemeenskap. Oor die aard van hierdie gemeenskap bestaan daar egter diepgaande verskille tussen Rome en Protestantisme.

(a) Kenmerkend van die Protestantse opvatting is dat "liggaam van Christus" dan uitsluitend verstaan word as die pneumatiese bestaanswyse van die kerk op grond van haar gemeenskap met die verhoogde Christus. Dit is die Gees wat hierdie gemeenskap konstitueer aangesien Christus deur sy Gees in sy gemeente woon en dit deur sy Gees besiel en vervul. In hierdie verband word van die "liggaam van Christus" dan ook gepraat as die onsigbare kerk of die mistieke unie tussen Christus en sy gemeente.

(b) In die tradisionele R.K. eksegese is die kerk as liggaam van Christus nie in die eerste plek pneumaties gesien nie maar as resultaat van die vereniging van die kerk met die God-menslike natuur van Christus. Bepalend

ia) Hiervoor kan J. J. Meuzelaar, a.w., p. 2-19 bv. geraadpleeg word.

8) A.w., p. 404 vv.; Kyk ook E. Percy, Der Leib Christi in den Paulinischen Homologumena und Antilegomena, Lund/Leipzig 1942, p. 9 vv. 
hiervoor is veral die wyse waarop die gemeente volgens Roomse opvatting deur die Mis deel kry aan die liggaam van Christus.

Die kerk kan dan .liggaam van Christus" genoem word omdat Christus in die kerk as't ware 'n uitbreiding van sy bestaan ontvang en hierdie verenigde bestaanswyse van Christus en sy kerk aangedui kan word as die "mistieke”- of "kollektiewe Christus”. Tog bly die metaforiese karakter bestaan want hoewel die kerk verenig word met die persoonlike liggaam van Christus, is sy self nie daardie liggaam nie maar slegs die totaliteit van dié met wie Christus Homself verenig.

Beide die Protestantse en R.K. opvatting gaan in hierdie oneintlike interpretasie uit van die kollektiewe betekenis van die liggaam as aanduiding van die organiese geheel van die gelowiges in sy vereniging met Christus. Die enigste verskil is dat die vereniging tussen Christus en sy kerk verskillend geïnterpreteer word.

(ii) Op hierdie tradisionele, oordragtelike uitlegging van die begrip "liggaam van Christus" is in die laaste dekades skerp kritiek gelewer sowel in Protestantse as R.K. kring. In Protestantse kring is die kritiek hoofsaaklik gerig teen die eensydig pneumatiese karakter wat aan hierdie liggaam van Christus toegeken is. In Roomse kring weer is dit gerig teen die kollektiewe uitbreiding wat die bestaan van Christus sou gekry het. Hoewel verskillend van gesigspunt en resultaat het hierdie tweërlei kritiek een ding in gemeen. Albei beweeg weg van die oneintlike opvatting en gaan oor tot die opvatting dat onder, ,liggaam van Christus" verstaan moet word sy eintlike-, persoonlike-, historiese- en verheerlikte liggaam.

Wat die kritiek in Protestantse kring betref word gewoonlik eerste gewys na E. Percy wat in sy bekende werk „Der Leib Christi", in die vroeë veertigerjare skerp kritiek gelewer het op die gedagte van die kerk as liggaam van Christus wat deur sy Gees gekonstitueer word en deur die Gees se inwoning besiel word. ${ }^{9}$ ) Die hoofmoment van Percy se kritiek is daarin geleë dat die tradisionele opvat-

9) Kyk E. Percy, a.w., p. 10 vv. 
ting die uitdrukking ,liggaam van Christus" verklaar het na analogie van ' $n$ dichotomisties verstane antropologie. Hierdie antropologiese siening is volgens Percy totaal vreemd vir Paulus en daarom kan dit nie gebruik word om die Pauliniese uitsprake mee te verklaar nie.

„Es muss somit im Lichte von dem, was sich über die paulinische Auffassung vom Menschen feststellen lässt, als in sehr hohem Grade unwahrscheinlich beurteilt werden, dass Paulus bei der Bezeichnung der Gemeinde als Leib Christi sich diese als einen von Christus beseelten Leib gedacht habe." ${ }^{11}$ )

'n Ander gewigtige beswaar wat deur Percy ingebring is, is dat die deur hierdie beeld aangeduide gemeenskap tussen Christus en sy gemeente uitsluitend gesien is as ' $n$ deur die Gees gekonstitueerde, geestelike of mistieke unie. Hierteenoor word gestel dat hierdie eenheid by Paulus in die eerste plek 'n heilshistoriese karakter dra, soos dit ook tot uiting kom in die formule en Christô ( $\mathrm{vgl}$. Rom. 12:5). Dit beteken dat op grond van Christus se plaasbekledende lyding en dood vir baie mense, hulle almal daardeur in Hom betrek is en so objektief sy liggaam is. Hiermee word nie ontken dat Christus deur sy Gees in die gemeente woon nie, maar dat vir hierdie geestelike gemeenskap die objektiewe, heilshistoriese eenheid van die "almal in een" ten grondslag lê en daaraan voorafgaan. „Ist somit von einer Abhängigkeit des einen Gedankens vom anderen die Rede, so ist es nicht das en Christô, das von en pneumati abhängt, sondern das en pneumati welches erst durch das en Christô seine volle christliche Bestimmtheit erhält. ${ }^{11}$ )

Die vraag kan tereg gestel word: wat moet ons dan nou verstaan onder die eenheid tussen Christus en sy gemeente volgens die beskouing van Percy? Hierop antwoord Percy dat die aanduiding van die gemeente as liggaam van Christus niks anders kan beteken nie as die inlywing van die gemeente in Christus self as die Gekruisigde en Opgestane. Die gemeente as liggaam van Christus val dus saam met Christus self. ..Dieser mit der Gemeinde identische Leib Christi ist deshalb im Grunde

10) Idem, p. 14

11) Idem, p. 36 . En op p. 38 verklaar hy: „Wir haben somit gefunden dass wir kein Recht haben, den Paulinischen Gedanken des Seins des Gläubigen in Christus durch den Geistgedanken zu interpretieren." Vgl. ook p. 43 bo aan. 
kein anderer als jener, der am Kreuze starb und am dritten Tage auferstand..."'12) Hier word duidelik elke afstand of oneintlikheid uitgewis en 'n identifikasie voltrek tussen die gemeente en Christus.

Voorlopig kan t.o.v. hierdie beskouing van Percy opgemerk word dat hy hier 'n sprong maak wat Paulus self nie gemaak het nie. Hoeseer die formule en Christô ook aanduiding kan wees van die gemeente se begrepenheid in Christus, is dit nog geen identiteitsuitspraak nie. Eenheid is nie identiteit nie en hoef dit nie te wees nie. Tog het Percy in beide Protestantse en Roomse kring steun vir sy standpunt gevind. By die Roomse eksegete loop hierdie beskouing daarop uit dat die kerk, deur haar te mag identifiseer met die verheerlikte liggaam van Christus, die volheid van die goddelike lewe ontvang omdat die verheerlikte liggaam van Christus in die hemel, die woonplek is van die volheid van sy Godheid. ${ }^{13}$ )

(iii) 'n Derde opvatting wat vermelding verdien, is die gedagte wat die voorstanders hiervan meen te vind in die O.T. en die laat-Jodendom. Dit is die gedagte van die ..Gesamtpersönlichkeit" of "corporate personality" waarvolgens 'n groep in verlede, hede en toekom soos ' $n$ indiwidu kan funksioneer in die lid wat die geheel verteenwoordig. As belangrike steun vir hierdie gedagte word dan verwys na die Adam-Christus parallelle in Rom. 5:12-21 en | Kor. $15: 22,45-49$. Soos Adam 'n ,corporate personality" is van die sondige mensheid, so is Christus dit as verteenwoordiger van die nuwe mensheid, die kerk. ${ }^{14}$ ) Sonder om die gedagte van verteenwoordiging van die baie deur die Een hier sondermeer af te wys, is dit 'n vraag of Paulus se gedagte die is van 'n "corporate personality" wanneer hy oor die gemeente as liggaam van Christus praat. Die verdere ondersoek na die bedoeling van Paulus sal hierop ' $n$ antwoord moet gee.

(iv) 'n Opvatting wat ons slegs in die verbygaan kan noem, is die gedagte dat ons in die liggaam-beeld met gnostiese of stoisynse invloede te make het. ${ }^{15}$ ) Hierdie beskouinge is

12) Idem, p. 44; So ook O. Michel, Der Brief an die Römer12 (Kritisch-exegetischer Kommentar Uber das N.T.). Göttingen 1963, p. 297. Vgl. ook O. Cullmann, a.w., p. 30.

13) Vgl. hiervoor H. N. Ridderbos, a.w., p. $410 \mathrm{v}$

14) Kyk J. J. Meuzelaar, a.w., p. 11 vv. vir die verteenwoordigers van hierdie standpunt; Kyk ook E. Schweizer, a.w., p. 168 v.

13) So bv. E. Käsemann, Leib und Leib Christi, Tübingen 1933; H. Schlier. Christus und die Kirche im Epheserbrief, Tübingen 1930; T. Schmidt, Der Leib Christi, Leipzig/Erlangen 1919. 
egter voldoende en grondig deur Percy ${ }^{16}$ ) e.a. weerlê sodat dit geen doel dien om verder daarop in te gaan nie. Ons moet nou aandag gee aan die Pauliniese uitsprake rondom hierdie gedagtekompleks soos dit voorkom in die Romeine- en I Korinthiërbrief maar daarnaas ook in die Efese- en Kolossensebrief. Die bedoeling is nie om willekeurig skeiding te maak tussen die uitsprake in die hoofbriewe en laasgenoemde briewe, of te veronderstel dat ons in Efese-Kolossense met 'n ontwikkeling in die Pauliniese gedagtegang te make het nie. Feit is net dat die beeld gekompliseer word deur die uitbreiding daarvan in laasgenoemde briewe naamlik dat Christus eksplisiet die Hoof (kephalê) van hierdie liggaam genoem word.

\section{DIE VERHOUDING LIGGAAM EN CHRISTUS IN ROMEINE EN I KORINTHE}

Gaan ons die tersaaklike uitsprake in hierdie briewe na dan merk ons in die eerste plek op dat dit in albei gevalle voorkom in ' $n$ paraenetiese samehang. In hierdie perikope gaan dit dus sonder twyfel om die oproep tot onderlinge eenheid en nederigheid te midde van die verskeidenheid van genadegawes en funksies in die gemeente. Dit word dan geillustreer deur die beeld van die organiese eenheid in verskeidenheid van die menslike liggaam. Dit sou egter naief wees om hierdie aspek as die enigsțe betekenis van hierdie beeld te wil handhaaf.15) Wat Paulus hier as imperatief van die gemeentes vereis, is gegrond in die indikatief van die feit dat die gemeente liggaam van Christus is (1 Kor. 12:12,27) en juis daarom een liggaam in Christus (Rom. 12:5). Hierdie twee formules naamlik die genetief konstruksie sôma Christou en die formule en Christô, is ook die enigste eksplisiete uitsprake betreffende die verhouding waarin hierdie liggaam tot Christus staan. Dit is 'n vraag of die genetief Christou iets meer aandui as besit en outoriteit. ${ }^{18}$ ) In elk geval is die enigste sleutel tot die verstaan van sôma Christou die formule en Christô.

15) A.w., p. 39 vv.; J. J. Meuzelaar, a.w., p. 8 vv.; O. Cullmann, a.w., p. 29 voetnoot 32; I. J. du Plessis. Christus as Hoof van Kerk en Kosmos, Groningen 1962, p. 20 v.

1i) Hierdie moontlikheid word tereg deur Ridderbos afgewys a.w., p. 413. Anders bv. F. W. Grosheide, De eerste Brief aan de Kerk te Korinthe (Commentaar op het Nieuwe Testament). Kampen 1957, p. 335. T.o.v. I Kor. 12:27 sê hy: „Alleen staat dit vast, dat in dit gehele hoofstuk niet de gedachte voorkomt: Christus het Hoofd, de gemeente Ziin lichaam, een beeld, dat de eenheid van Christus met de zijn voorstelt. Daarvan is hier geen sprake."

1v) Vgl. bv. C. K. Barrett, The first Epistle to the Corinthians (Black's New Testament Commentaries) London 1968, p. 292; A. Schlatter, Paulus der Bote Jessu, Eine Deutung seiner Briefe an die Korinther". Stuttgart 1969, p. 345; en ook weer F. W. Grosheide, a.w., ad loc. 
Ons is daarvan bewus dat hierdie formule deur Paulus in verskillende betekenis-nuanses gebruik word. Al het verskeie navorsers die teendeel probeer bewys, kan ons met sekerheid aanvaar dat Paulus nêrens met hierdie formule 'n mistieke eenheid met Christus in die oog het nie. ${ }^{19}$ ) Ridderbos ${ }^{20}$ ) verklaar dit so dat hierdie formule dui op die deelkry van die gelowige aan die heil wat Christus deur sy kruisdood gebring het en sien die sleutel tot hierdie verstaan van en Christô in die Adam-Christus parallel. Die gelowiges is dus korporatief inbegrepe by wat Christus deur sy verlossingsdaad vir hulle beteken. Dit hou in dat hierdie in-Christus-wees 'n heilswerklikheid is wat "het begrepen zijn van de velen in de Eén, het gerepresenteerd worden van de gemeente door Christus aanduidt. ${ }^{21}$ ) Dit hou verder in dat die Gees nie hierdie in-Christus-wees konstitueer en eers moontlik maak nie. Daarom verklaar Ridderbos: „Hiermee is dan tevens de opvatting weerlegd, als sou de gedachte van het lichaam van Christus berusten op de pneumatische inwoning van Christus in zijn gemeente. ${ }^{\prime 22}$ ) Dit sou volgens Ridderbos dichotomisties wees want die één liggaam is nie in die eerste instansie in pneumatiese nie maar wel 'n heilshistoriese, voorwerplike eenheid. $\mathrm{Hy}$ ag die pneumatiese wel vir die verdere realisering van hierdie liggaamseenheid van oorwegende belang, maar stel dat die volgorde nie: Christus - die Gees - die liggaam is nie, maar wel: Christus - die liggaam in Christus — die Gees.

Ridderbos wys verder daarop dat die uitspraak in I Kor. 12:13 nie daarop dui dat die eenheid van die liggaam deur die Doop tot stand gebring word nie, maar dat die dopeling in betrekking gebring word tot ' $n$ reeds bestaande persoon of eenheid. Die dopeling word dus ingelyf in die reeds bestaande liggaam, ${ }^{23}$ ) en daarom word nie aan die Gees gedink as die liggaam-konstituerende faktor nie, maar as die gawe wat die gelowiges kragtens hulle inlywing in. die Jiggaam deelagtig word. Dit is nie die Gees wat deur middel van die Doop in die liggaam inlyf nie; die omgekeerde is waar, naamlik dat die inlywing deur die Doop, ook gedoop-word-met-die-Heilige-Gees beteken. ${ }^{24}$ )

Om Ridderbos se argumente saam te vat: Hy wys identifikasie met die historiese- en opgestane liggaam van Christus af. Die een-

\footnotetext{
19) So tereg R. Bultmann, Theologie des Neuen Testaments, ${ }^{6}$ Tübingen 1968, p. 328; W. G. Kümmel, Die Theologie des Neuen Testaments, Göttingen 1969 , p. 196; H. N. Ridderbos, a.w., p. 57 v. en vele ander.

211) A.w., p. 56 vv.

21) Idem, p. 414

22) Idem, p. 415

23) So ook E. Percy, a.w., p. 16. H. Conzelmann, Der erste Brief an die Korinther (Kritisch-exeqetischer Kommentar über das N.T.). Göttingen 1969, p. 249, voetnoot 13: Anders C. K. Barrett, a.w., p. 288; H. D. Wendland, Die Briefe an die Korinther (N.T.D.), Göttingen 1968, p. 111 v.

24) Kyk H. N. Ridderbos, a.w., p. 416.
} 
heid tussen Christus en die liggaam word nie bewerkstellig deur die pneumatiese inwoning van Christus in die gemeente, of deurdat die Heilige Gees die eenheid konstitueer nie. Die eenheid is die heilshistoriese begrepenheid van die vele in die Een. Die kwalifikasie van die gemeente as liggaam van Christus het dus duidelik 'n oneintlike, metaforiese betekenis, hoe reël die daardeur uitgedrukte eenheid ook mag wees. ${ }^{25}$ )

Ons kom later op hierdie argumente van Ridderbos terug en wend ons nou eers na die uitsprake in Efesiërs en Kolossense.

\section{DIE VERHOUDING LIGGAAM EN HOOF BY EFESIERS EN KOLOSSENSE}

Hoewel die liggaam - beeld vir die kerk in Efesiërs - Kolossense saaklik in dieselfde betekenis gebruik word as in Romeine 1 Korinthiërs, vind hier ' $n$ nadere toeligting of omskrywing plaas deurdat Christus uitdruklik die Hoof van hierdie liggaam genoem word. ${ }^{n a}$ ) Wanneer ons die relevante uitsprake nagaan dan merk ons dat kephalê nie in elkeen van die gevalle sondermeer met Hoof weergegee kan word in die konteks waarin dit gebruik word nie. $\checkmark a n$ die verstaan van die betekenis van kephalê in die betrokke gedeeltes hang vanselfsprekend af die verstaan van die verhouding van liggaam en Hoof in hierdie briewe. Wat het die outeur in elke geval met kephalê probeer uitdruk, of watter agtergrond moet vir hierdie term veronderstel word in die samehang waarin dit hier gebruik word?

Kephalê het in die gewone Griekse gebruik benewens die normale aanduiding vir ",kop" ook die betekenis van begin, owerste, leier, aanvoerder gekry. ${ }^{27}$ ) en hierdie gebruik is ook aanwysbaar vir die LXX waar kephalê hoofsaaklik die vertaling is van rô'š. ${ }^{28}$ ) Het hierdie betekenis(se) enige rol gespeel in die Skrifgedeeltes wat ter sprake is? Die kontekse waarin die begrip gebruik word kan 'n belangrike bydrae lewer.

Dit is opvallend en meer as betekenisvol dat waar die term kephalê vir die eerste keer gebruik word in albei hierdie briewe, dit geplaas is in ' $n$ konteks waar Christus lof toegesing word as Skepper en kosmiese Heerser, wat oor die magte oorwin het en nou aan die regterhand van God sit.

Van alles word $\mathrm{Hy}$ die archê (Kol. 1:18) genoem en in die skepping is $\mathrm{Hy}$ die eerste in rang (prôtotokos Kol. 1:15). In hierdie kontekse is dit dus gewis Jesus Christus as begin van alles, en as

25) Idem, p. 419.

26) Ef. 1:22; 4:15; 5:23; Kol. 1:18; 2:10; 2:19

27) Anders $S$. Bedale. The Meaning of Kephalê in the Pauline Epistles, The Journal of Theological Studies, Vol. V. 1954, p. 211.

25) Kyk H. Schlier, T.W.N.T. III, p. 673. 
Heer oor alles wat op die voorgrond staan. ${ }^{29}$ ) Waar Christus in die kader van hierdie uitsprake in Ef. 1:22 kephalê huper ta panta genoem word, kan kephalê geen ander betekenis hê as „Heer" van alles nie. Sy hoofskap van die kerk volgens Kol. 1:18 en die feit dat die kerk sy liggaam is, dui wel op 'n besondere verhouding, maar kephalé blyk hier nie 'n ander betekenis te hê as „Heer" van die kerk nie.

Dit wil daarom voorkom dat kephalê hier nie die beeld van liggaam daarby nodig het om sin te maak nie. Dit sou met ander woorde net so goed by ekklêsia kon staan. Hy is Hoof van die liggaam omdat $\mathrm{Hy}$ Heer van die liggaam is. ${ }^{30}$ ) Ons het hier dus nie met in saamgestelde organiese metafoor te doen as sou Christus as die Hoof die vernaamste liggaamsdeel wees, wat toegevoeg tot die gemeente as romp, die totaliteit van Hoof en liggaam vorm nie. ${ }^{31}$ ) In lyn hiermee verklaar H. J. Gabothuler: „Kephalê ist Christus nicht darum, weil er in organischem Zusammenhang mit dem Kosmos (oder) Leib steht, sondern weil er Herr ist: über die Mächte (und) über die Kirche. ${ }^{.32}$ )

Twee tekste wek egter wel die indruk asof dit om een of ander organiese verbintenis gaan, te wete Ef. 4:15 v. en Kol. 2:19. In albei is sprake van die liggaam wat uit Christus as die Hoof die wasdom ontvang terwyl in Ef. ook nog vermeld word dat die gemeente na Hom toe (eis auton) groei. 'n Liggaam wat na die hoof toe groei is moeilik denkbaar, sodat hierdie uitsprake vreemd opval as hulle die bedoeling het om 'n organiese proses weer te gee. Dit is verder opmerklik dat in albei hierdie gevalle die konstruksie van die bysinne in plaas van die verwagte ex hês wat op kephalê moes volg, die manlik enkelvoud van die voornaamwoord gebruik word naamlik ex hou. Dit beteken dat die liggaam nie uit die Hoof groei nie maar uit Christus.

Wanneer in Ef. 5:22 v. verklaar word dat die man die hoof van die vrou is soos ook Christus van die gemeente, dan gaan dit klaarblyklik in die eerste plek om onderworpenheid. Maar hierdie voorrangsposisie spruit uit die feit dat Christus die verlosser en behouer van die gemeente is. Dit beteken t.o.v. die verhouding van Christus en sy gemeente, dat die gemeente in Christus sy oorsprong het en van Hom vir die voortbestaan afhanklik is.

Die selfstandige plek wat kephalê inneem, laat duidelik blyk dat ons hier nie met een en dieselfde metafoor te doen het nie maar met twee. Terwyl die twee met mekaar in noue verband gebring kan

29) Vgl. I. J. du Plessis, a.w., p. 108; J. J. Meuzelaar, a.w., p. 117, vv.

:") Vgl. R. P. Martin. Colossians, Michigan 1972, p. 47.

31) H. N. Ridderbos, a.w., p. 424

::) Jesus Christus. Haupt der Kirche - Haupt der Welt (A.T.A.N.T. 45) Züricht/Stuttgart 1965, p. 152. 
word, het elkeen tog 'n selfstandige betekenis en bestaan. „De qualificatie ,hoofd' heeft haar eigen zelfstandige betekenis, ongeacht of daarmee het overdrachtelijk spreken van een ,lichaam' verbonden wordt. ${ }^{33}$ )

As hierdie bevinding korrek is, beteken dit dat die beeld liggaam as aanduiding van die gemeente 'n volledigheid aandui waarby ook die hoof as lid veronderstel word. Dit is duidelik Paulus se bedoeling in I Kor. 12. Hy vermeld in vers 21 die hoof as lid van hierdie liggaam soos enige ander lid dit is, met ander woorde Paulus dink hier nie aan die gemeente as 'n romp waarvan die hoof ontbreek nie. Word die term liggaam in die hoofbriewe sowel as in Efesiërs - Kolossense slegs in metaforiese betekenis gebruik, dan is dit minstens aanduiding van 'n gemeenskap wat op besondere wyse in 'n eenheid saamgesnoer is en saam bestaan en fungeer. Hierdie beeld word gebruik omdat dit soveel van die kenmerke van die kerk so treffend vitdruk.

Tot hier skep die beeld geen probleme nie. Dit is eers wanneer ons begin vra na die verbintenis tussen die gemeente as liggaam en Jesus Christus wie se liggaam dit is, dat die interpretasie probleme na vore kom. Ons kom nie by die feit verby dat die gemeente „liggaam van Christus" genoem word nie. As hier slegs prake was van soos 'n liggaam in Christus, dit wil sê alleen metafories bedoel, dan het ons geen verklaringsprobleem gehad nie.

Deur egter wel van die gemeente as liggaam van Christus te praat, het Paulus klaarblyklik die oog op 'n besondere relasie tussen Christus en sy gemeente. Dat hierdie verhouding 'n objektiewe werklikheid is, wat reeds deur die plaasvervangende heilsgebeure in werklikheid geword het, kan nie ontken word nie.

Dit is met ander woorde 'n vraag of die deel kry van die gelowige aan die heil in Christus, eers deur die Gees moontlik gemaak word: Dit wil voorkom of Ridderbos se argument dat die eenheid tussen die liggaam en Christus nie deur die Gees gekonstitueer word nie, steun vind in die vroeg-christelike dooppraktyk. Volgens Hand. 2:38; 8:14 v. en 19:5 v. is die wat gelowig geword het, in die Naam van die Here Jesus gedoop en eers dan het die gawe van die Heilige Gees gevolg. Selfs by die doop van Cornelius waar die uitstorting van die Heilige Gees aan die Doop voorafgegaan het, kry 'n mens nie die indruk dat die gawe van die Gees ten nouste saamgehang het met die doopgebeure nie. Waar Paulus in Rom. 6 die Doop beskrywe as saam begrawe word en saam opstaan met Christus, en so die deel kry aan die lewe in Christus, maak hy ook nie melding van die Heilige Gees nie.

23) H. N. Ridderbos. a.w., p. 426. 
Dit is egter 'n vraag hoe ons I Kor. 12:13 moet verstaan. Die interpretasies loop uiteen op hierdie punt. Dit wil egter voorkom asof Paulus hier minstens in gedagte het dat die Gees die eenheid tussen die lede onderling konstitueer, of hulle nou Jode of Grieke is, slawe of vry mense. Moet ons nou aanvaar dat die werk van die Gces slegs beperk is tot die samebinding van die lede onderling. Dit is bekend dat Paulus om die beurt kan praat van die inwoning van Christus of van die Heilige Gees in die gemeente (vgl. Rom 8:10 met 8:11); dat hy kan praat van die Gees van Christus (Rom. 8:9), en Christus en die Gees selfs met mekaar kan identifiseer (II Kor. 3:17).

Al hierdie uitsprake van Paulus dui in die eerste plek op 'n funksionele eenheid of werksidentiteit van Christus en die Gees. Deur sy Gees is Christus dus self in sy gemeente teenwoordig en werksaam en waar die Gees nie woon en werk nie, daar behoort niemand aan Christus (Rom. 8:9) nie. Dit lyk dus asof Paulus nie dink aan gemeenskap (koinônia) tussen Christus en die gelowige of sy gemeente sonder dat die Gees hierdie gemeenskap werk nie. Daarom kan Paulus in I Kor. 6:17 ook sê dat wie die Here aanhang een Gees met Hom is. ${ }^{: 4}$ ) Sou dit ook kon beteken dat wie nie deel het aan die Gees van Christus nie, ook nie deel aan Christus kan hê nie? Alles wys in hierdie rigting.

\section{SAMEVATTING}

Ons vat dus saam. Paulus gebruik die liggaam-beeld om wesenlike kenmerke van die gemeente mee aan te dui. Hierdie metafoor het egter sy grense, en wanneer hierdie grense deurbreek word, stuit ons op teensprake. Die bestaan van die gemeente en die verhouding van sy lede onderling kan nie net met 'n liggaam vergelyk word nie, die gemeente is ook liggaam van Christus waarvan Christus die Hoof is. Die liggaam kan nie sonder sy Hoof wees nie, maar die Hoof is ook nie sonder sy liggaam nie. Hierdeur word 'n besondere relasie aangedui maar ook ' $n$ deel hê van die liggaam aan die heilsgoedere, wat deur die heilsgebeure in Christus die eiendom van die gemeente geword het. Hierdie heilstoestand is ' $n$ objektiewe werklikheid deur die volbragte heilswerk van Christus, maar kan alleen subjektief gerealiseer word deur die werk van die Heilige Gees. Maar waar die Heilige Gees werk en aan die heil deel gee, is Christus self werkend teenwoordig. Die eenheid is in Christus maar dit is die Gees wat deel daaraan gee. Dit is geen dichotomisme nie. Die Gees word nooit statiese attribuut van hierdie

:i1) Dat hier ' $n$ aktiwiteit van die Heilige Gees veronderstel word, word gesteun deur F. W. Grosheide, a.w., p. 174; H. N. Ridderbos, a.w., p. 416 v.; Vgl. ook H. D. Wendland, a.w., ad loc. 
liggaam nie. Hy bly die gans andere, wat alleen die lewe in die Pneuma moontlik maak as 'n gawe van skepping en vernuwing in verbondenheid aan Jesus Christus.

Vir die gemeente is hierdie liggaam-van-Christus-wees in die laaste instansie 'n geloofswerklikheid, maar nie daarom minder werklikheid nie. By dit alles bly dit egter, om die woorde van die Efesiërbrief te gebruik: 'n groot mustêrion (Ef. 5:32). 